\title{
Diagnosis and management of gastrointestinal chemical burns and post-burn oesophageal stenosis
}

\author{
Piotr Obarski, Janusz Włodarczyk \\ Department of Thoracic and Surgical Oncology, Jagiellonian University Medical College, John Paul II Hospital, \\ Krakow, Poland
}

Kardiochirurgia i Torakochirurgia Polska 2021; 18 (4): 252-259

\begin{abstract}
Post-burn oesophageal stenosis occurs as a result of accidental or intentional ingestion of a corrosive substance. Global estimates indicate tens of thousands of acid or lye ingestion cases per year. In some cases patients in the early post-burn phase require urgent surgical intervention. Endoscopy, along with chest and abdominal computed tomography, form the basis of diagnosis. The need for emergency oesophageal or gastric resection is associated with a high mortality rate of up to $60 \%$. Postburn oesophageal stenosis is a challenging clinical problem that requires coordinated multispecialty treatment. The treatment of post-burn stenosis may be with endoscopic techniques or reconstructive surgery. Surgical reconstruction is performed once the scar has definitively formed. The extent of the injury, anatomical conditions, previous surgery and the team's expertise determine the optimum reconstructive method. In this article, we present the current knowledge on the diagnosis and treatment of oesophageal burns.
\end{abstract}

Key words: caustic ingestion, corrosive stricture, oesophageal reconstruction.

\section{Introduction}

Accidental or suicidal ingestion of a chemical corrosive substance can result in gastrointestinal and respiratory burns. The circumstances of the incident and the chemical nature of the substance determine the extent of injury and toxicological risk. The initial period after a chemical burn is associated with the possibility of laryngeal oedema, perforation of the oesophagus, stomach and intestine, gastrointestinal bleeding and pancreatitis [1-3]. Severe upper gastrointestinal burns affect $10-33 \%$ of adult patients, with mortality rates of up to $10 \%[3,4]$. Patients requiring either an emergency oesophageal resection due to mediastinitis or a gastrointestinal resection due to peritonitis have a more severe course of illness, with a higher risk of death. In this group, perioperative mortality ranges from $15 \%$ to $60 \%[5,6]$. Late sequelae of irritant burns include retrograde changes in the oral cavity, oesophagus, stomach or respiratory system. Furthermore, the healing process may lead to stricture formation within these organs. Stricture formation may lead to severe systemic sequelae for the patient, including poor general condition, significant weight loss, malnutrition-related illness, recurrent aspiration leading to respiratory infections, and potentially respiratory failure. Patients usually require preparation for elective surgery, including reversal of any metabolic disturbances and optimisation of respiratory function. The most common late complication of endoscopically confirmed chemical oesophageal burns is stricture formation, which occurs in approximately a quarter of hospitalised patients [7]. Oesophageal strictures resulting from chemical burns are considered more difficult to treat both endoscopically and surgically than post-reflux or neoplastic strictures [8].

\section{Epidemiology}

Chemical burns of the oesophagus are estimated to affect several tens of thousands of people per year, of which $80 \%$ are in children under five years of age [1-5]. According to the Annual Report of the American Association of Poison Control Centers' National Poison Data System, 5-15 thousand oesophageal burns are reported annually in the USA, with an incidence of 1.08/100,000 [9]. Accidents involving children usually occur in the home and typically involve ingestion of a small amount of a chemical substance. Ingestion of corrosive substances by adults tends to have a suicidal background or is the result of a mistake. The amount ingested by adults tends to be higher than in children, and leads to more significant injuries of the upper gastrointestinal and respiratory tracts. Similarly, ingestion of toxic substances in industrial settings, where substances are found

Address for correspondence: Piotr Obarski MD, Department of Thoracic and Surgical Oncology, Jagiellonian University Medical College, John Paul II Hospital, Krakow, Poland, e-mail: piotr.obarski@gmail.com Received: 14.07.2021, accepted: 19.09.2021. 
in higher concentrations, has more severe consequences $[1,10]$. Table I provides a summary of the chemicals that most commonly lead to burns.

\section{Pathophysiology}

Ingestion of acids and bases, despite their different pathomechanisms of injury, lead to similar consequences; alkalis more commonly damage the respiratory tract and proximal part of the oesophagus, whereas acids tend to damage the oesophagus, stomach, duodenum and small intestine $[1,3,10]$. The extent of injury to the gastrointestinal and respiratory tract organs is determined by the volume, concentration, molarity and hydrophilicity of the ingested substance, and its duration of contact with tissue. Contact of a base with tissue induces diffuse necrosis, hydrolysis of lipids and damage to the mucosa. The base quickly penetrates deep into the organ wall, causing an intense inflammatory reaction within the immediate and surrounding tissue. Deep damage by acids is exacerbated by intravascular coagulation, as acids cause tissue dehydration and protein denaturation, leading to necrosis and superficial clot formation. Superficial clot formation and the natural properties of the stratified squamous epithelium may provide protection to the deeper layers of the oesophagus $[3,10]$. However, this view is challenged by studies that show no significant differences in the depth of gastrointestinal injury in relation to the causative agent [10]. Deep gastrointestinal wall damage results from the direct action of the substance and the subsequent inflammatory process, including thrombosis of submucosal vessels and bacterial colonisation.

\section{Symptoms}

Ingestion of a corrosive substance in small amounts may be asymptomatic and may not have any significant sequelae. In $70 \%$ of burns of the oral cavity, the oesophagus remains unaffected [1]. Among adults, $10-33 \%$ of burns have a severe course requiring treatment, with a mortality rate of up to $10 \%[3,4]$. Post-burn oesophageal stenosis is found in approximately $1-2 \%$ of burn patients [3, 4]. Among patients hospitalised with endoscopically confirmed oesophageal burns, oesophageal stenosis is the most common complication, affecting $24 \%$ of patients. Other complications include aspiration pneumonia in $11.36 \%$ and respiratory failure in $7.69 \%[9,11]$.

Ingestion of a corrosive substance not only may cause burns but also may have toxicological effects. Acid poisoning may lead to kidney and liver failure, haemolysis and intravascular coagulation. Hydrogen fluoride poisoning may cause severe hypocalcaemia. Phenol, zinc chloride and mercuric chloride are also toxic corrosives. Therefore, the nature of the causative agent and its toxicological profile must also be considered during treatment $[1,3,10]$.

It can be difficult to estimate the severity of burns based on clinical symptoms; therefore, patients often require advanced diagnostics [12].
Table I. Corrosive agents

\begin{tabular}{|c|c|}
\hline Type & Examples \\
\hline $\begin{array}{l}\text { Bases } \\
\mathrm{pH}>11\end{array}$ & $\begin{array}{l}\text { - Sodium and potassium bases (kitchen cleaners, pipe } \\
\text { cleaners, round batteries, homemade soap) } \\
\text { - Lithium and calcium alkalis (hair straightening products) } \\
\text { - Lithium and calcium bases (hair straightening products) } \\
\text { - Ammonia (cleaning agents) } \\
\text { - Sodium carbonate (agricultural drying of fruits) }\end{array}$ \\
\hline $\begin{array}{l}\text { Acids } \\
\mathrm{pH}<3\end{array}$ & $\begin{array}{l}\text { - Sulphuric acid (batteries, rechargeable batteries, } \\
\text { industrial cleaning products) } \\
\text { - Hydrogen chloride (solvents, deodorisers, toilet cleaners) } \\
\text { - Phosphoric acid (toilet cleaners) }\end{array}$ \\
\hline Other & - Bleaches, potassium permanganate \\
\hline
\end{tabular}

In general, there is no correlation between the results of laboratory tests and the severity of oesophageal burns. Leukocytosis on admission $>20,000 / \mathrm{mm}^{3}$ is one of the parameters which correlates with a high risk of death [13]. $\mathrm{pH}<7.22$ and $\mathrm{BE}<-12$ are considered markers of severe post-burn oesophageal damage.

\section{Chest X-ray and abdominal X-ray}

An overview chest $X$-ray and abdominal X-ray on admission are used as part of the initial assessment. Chest X-ray may reveal oesophageal perforation, pneumomediastinum, pleural fluid or pneumothorax, and abdominal X-ray may show free air under the diaphragm, indicating gastroesophageal perforation. Subsequent chest X-ray examinations are used to assess for pulmonary complications. Oesophageal perforation may also be diagnosed by the presence of extra-oesophageal streaking of aqueous contrast (Figure 1).

\section{Computed tomography (CT)}

Neck, chest and abdominal CT are standard examinations in patients with upper gastrointestinal burns to investigate for perforation or partial oesophageal wall damage, which can have severe consequences [1]. Studies by Bruzzi et al. and Ryu et al. demonstrated the high sensitivity of $\mathrm{CT}$ in assessing damage to consecutive layers of the oesophagus and suggest that CT evaluation with contrast can replace endoscopic examination, which often cannot or should not be performed in the acute phase of burns. CT can also assist in distinguishing patients who are at risk of developing oesophageal obstruction (Table II) [14, 15].

Patients with CT findings consistent with grade 3 or 4 oesophageal burns are at greater risk of developing oesophageal stenosis [14] (Table III).

In a study by Bruzzi et al. [15], the risk of developing stenosis in grade I, Ila and IIb burns was $0 \%, 17 \%$ and $83 \%$, respectively. Patients with grade III burns typically underwent oesophageal resection and were thus excluded from the study.

CT findings indicating full-thickness necrosis during the initial phase of the burn have also been established 


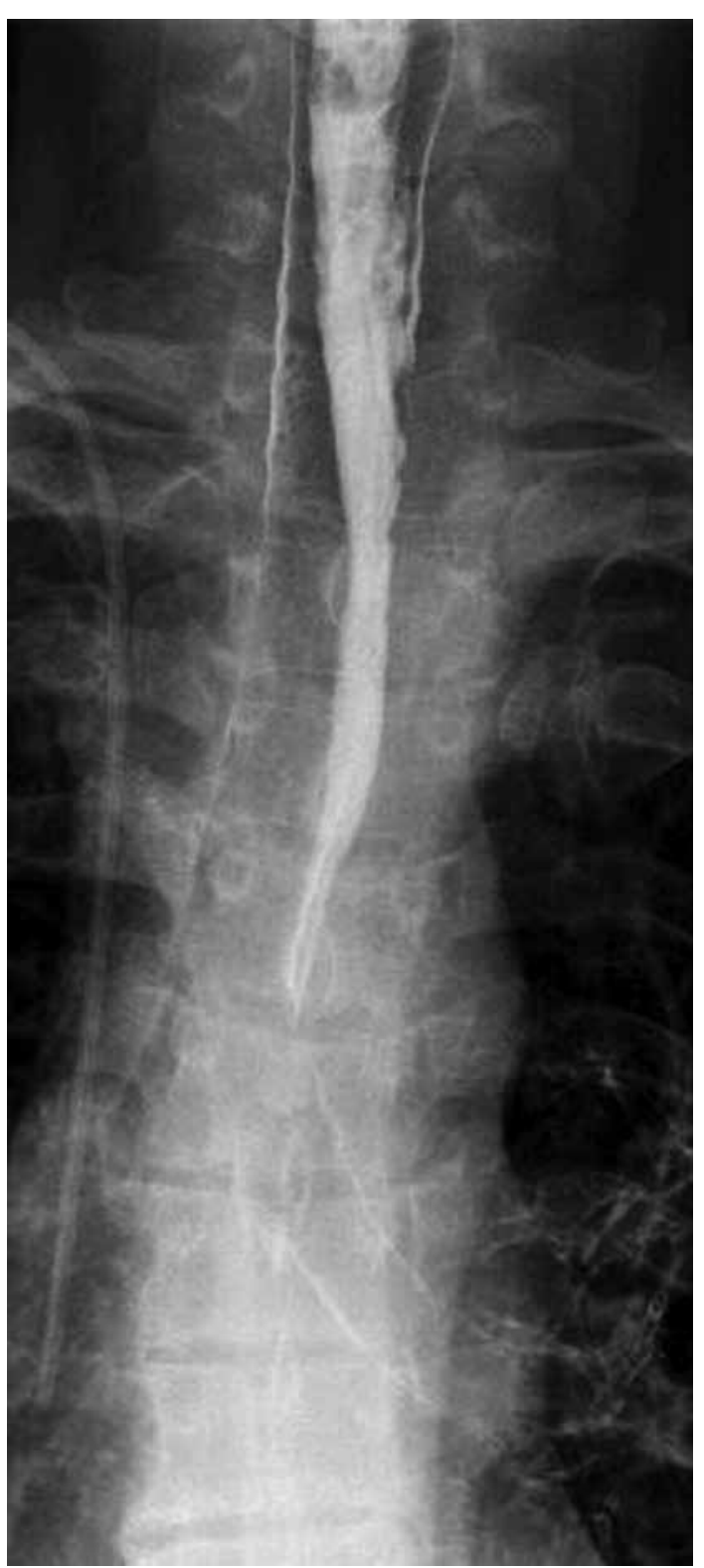

Figure 1. This X-ray shows oesophageal obstruction around the left main bronchus, with evidence of proximal oesophageal dilatation and the presence of contrast of the bronchial tree due to aspiration

as a predictor of post-burn stenosis. The authors demonstrated that a non-contrast phase CT image in keeping with a grade 4 burn, according to Ryu et al., showing blurring of the boundaries between layers of the oesophageal wall, obliteration of the perioesophageal tissue, and lack of postcontrast enhancement of the oesophageal wall, is a reliable predictor of post-burn stenosis [2, 15].

\section{Endoscopy}

Considering the pathophysiology of oesophageal burns, it is deemed safe to perform oesophagogastroduodenoscopy (OGD) up to 48 or even 96 hours after the burn in order to perform an early assessment [1]. In children, deep sedation or general anaesthesia is required, and therefore indications for endoscopy in a child should be considered
Table II. Oesophageal burn grading based on CT findings, based on Ryu et al. [14]

\begin{tabular}{ll}
$\begin{array}{l}\text { Burn } \\
\text { (grade) }\end{array}$ & CT findings \\
\hline 1 & No swelling of the oesophageal wall \\
\hline 2 & $\begin{array}{l}\text { Swelling and thickening of the oesophageal wall, without } \\
\text { involvement of the perioesophageal tissues }\end{array}$ \\
\hline 3 & $\begin{array}{l}\text { Swelling and thickening of the oesophageal wall with } \\
\text { involvement of the periesophageal tissues, well- } \\
\text { demarcated layers }\end{array}$ \\
\hline 4 & $\begin{array}{l}\text { As grade 3, with blurring of the boundaries between } \\
\text { tissue layers or localised fluid collections around the } \\
\text { oesophagus or descending aorta }\end{array}$ \\
\hline
\end{tabular}

Table III. Oesophageal burn grading based on CT findings, based on Bruzzi et al. [15]

\begin{tabular}{ll} 
Grade & CT findings \\
\hline Ila & $\begin{array}{l}\text { Normal, no oedema, homogeneous contrast enhancement } \\
\text { swelling, hypodensity of the oesophageal wall, contrast } \\
\text { enhancement of the peri-oesophageal tissue; target sign }\end{array}$ \\
\hline Ilb $\quad \begin{array}{l}\text { Necrotic mucosa without enhancement, homogeneous } \\
\text { annular enhancement of the outer oesophageal wall }\end{array}$ \\
\hline III & $\begin{array}{l}\text { Complete lack of enhancement of the oesophageal wall } \\
\text { indicating full-thickness necrosis }\end{array}$ \\
\hline
\end{tabular}

Table IV. Burn grade based on endoscopy findings, based on Zargar

\begin{tabular}{|c|c|}
\hline Grade & Endoscopy findings \\
\hline 0 & Normal endoscopic examination \\
\hline I & Hyperaemia and oedema of the mucous membrane \\
\hline Ila & $\begin{array}{l}\text { Friable mucosa with petechiae and erosions; } \\
\text { pseudomembranes and superficial ulcerations may also } \\
\text { be visible }\end{array}$ \\
\hline Ilb & $\begin{array}{l}\text { As grade Ila plus deep discrete or circumferential } \\
\text { ulcerations }\end{array}$ \\
\hline IIla & $\begin{array}{l}\text { Massive, congestive ulcerations and small necrotic foci } \\
\text { (grey, brown or black) are present }\end{array}$ \\
\hline IIIb & As in IIla with extensive necrotic foci \\
\hline
\end{tabular}

on an individualised basis. Routine endoscopy in children is supported by the results of studies demonstrating the presence of severe oesophageal injuries in $12-35 \%$ of asymptomatic cases [16]. Deep lower pharyngeal burns, severe burns of the respiratory tract, poor general condition and evidence of gastrointestinal perforation on imaging studies are considered relative contraindications for OGD. Endoscopic assessment of the injury makes it possible to predict the severity of the course and the risk of complications, including the development of stenosis [17]. The most commonly used oesophageal burn scale used in endoscopy is described by Zargar's studies [1, 11, 17] (Table IV).

Studies involving endoscopic examination have demonstrated that serious complications such as bleeding, fistula formation and perforation can be expected in grade IIa-III 
burns. Oesophageal strictures in both children and adults are formed following burns of at least grade Ila, and most commonly in grades IIIa and IIIb [11].

\section{Treatment}

The guidelines currently available are based on the results of a small number of studies, usually retrospective, without randomisation, or a case series [1, 2]. Therefore, they do not hold significant weight in terms of evidencebased medicine. In an attempt to systematise current knowledge, the World Society of Emergency Surgery (WSES) issued a set of recommendations in 2015 [2]. These recommendations suggested that the management of acute oesophageal burns in most cases is conservative.

First, the risk of laryngeal oedema should be assessed and, if dyspnoea is increasing, intubation or tracheostomy should be performed [1]. At the scene of the accident, the type and amount of substance ingested should be determined, as well as the nature of the event (suicidal, accidental). Vomiting should not be induced, nor should antacids be used due to the risk of secondary burn with regurgitated gastric contents or as a result of an exothermic reaction [2].

Early endoscopy (up to 48 hours, but preferably within 6-12 hours) combined with CT scanning allows assessment of the extent of the burn, the need for emergency surgical treatment and the risk of oesophageal stenosis [1-3]. Patients without features of oesophageal burns, or with burns in grades I or Ila on the Zargar scale, and with no significant burns of the oral cavity, pharynx or larynx, can be discharged from hospital after 48 hours of observation [18]. Patients with greater than grade Ila burns require prolonged inpatient observation or hospitalisation in an intensive care unit.

Indications for emergency oesophageal resection include:

- oesophageal perforation,

- mediastinitis, or

- compatible CT and endoscopic findings (grade IIIb burns) indicating full-thickness necrosis. If the $\mathrm{CT}$ result is not compatible with endoscopic imaging, conservative treatment is indicated [2]. The need for abdominal intervention is determined primarily by peritoneal symptoms or massive haemorrhage. During emergency laparotomy, the aim should be to remove all damaged organs (e.g. stomach, and if necessary, duodenum, pancreas, gallbladder, small bowel and transverse colon) [2, 5] The efficacy of a twostage procedure (the so-called "second look" surgery) has not been proven, as there is inevitable penetration of the corrosive substance through the organ walls within the first hours after the burn and therefore all affected tissues should be removed during one procedure [2].

\section{Pharmacotherapy and prevention of stenosis}

Proton pump inhibitors are routinely used, but there is no evidence that prophylaxis of acid reflux significantly reduces the risk of oesophageal stenosis. A gastric probe is also routinely used, which helps to decompress the stomach and provides a route for nutrition. The presence of the probe prevents complete scarring of the oesophageal lumen and allows subsequent dilatation procedures. However, it is possible that the presence of the probe may trigger a foreign body reaction and gastroesophageal reflux, and therefore may promote the development of stenosis $[1,2,18]$. Currently, routine use of steroids is not recommended except for indications arising from pulmonary complications [2]. Broad-spectrum antibiotic therapy is often used together with steroids in the treatment of pulmonary complications and as part of the management of septic shock $[2,18]$.

Zargar grade Ila-IIlb burns are likely to lead to oesophageal or gastric strictures, which require endoscopic treatment as a first step. These strictures are classified as complex due to their length $>2 \mathrm{~cm}$, multilevel nature and tortuous course. The efficacy of dilatation of post-burn stenoses is lower than dilatation performed due to reflux, and the risk of perforation is higher $(0.4-32 \%)[1,2,18]$. Endoscopic dilatation is commended around three weeks after the burn, with subsequent procedures repeated every 1-3 weeks [1, 2]. Studies on the local administration of steroids (triamcinolone) or antimetabolites (mitomycin C), as well as stenting of the oesophagus, have been shown to prolong the dysphagia-free time between successive dilations, and in a few cases, eliminated the need for further interventions [1, 2, 8, 18]. Post-burn stenosis is estimated to develop a minimum of six months after the burn, after which time surgical treatment can be considered [2,19].

\section{Surgical treatment of oesophageal stenosis}

Planning of surgical treatment of patients with postburn stenosis of the oesophagus or stomach requires assessment of the patient's nutritional status, the level and length of the stenosis, any concomitant injuries, including strictures of the oral cavity, pharynx and larynx, and the presence of fistulas involving the bronchial tree $[2,4]$. Post-burn stenosis of the pyloric part of the stomach precludes the use of this region during reconstructive surgery. Impaired gastric emptying is an indication for antrectomy or small bowel bypass anastomosis [2]. Post-burn oesophageal stenosis requires oesophageal resection or bypass surgery. Oesophageal resection may be preferred due to the increased risk of tumour development in the burn scar [20-22]. Considering that neoplastic transformation occurs after 20-40 years, oesophageal scar removal is justified mainly in children and young adults [2]. Oesophageal bypass surgery without resection is particularly popular in Far Eastern countries [23]. Bypass is acceptable where the oesophageal obstruction is located at or above the level of the upper thoracic orifice and in cases of incomplete oesophageal obstruction, where the distal segment drains to the stomach. Leaving an obstructed portion of the oesophagus in the thoracic segment may lead to the development of mucocele, which can exert pressure on adjacent organs and lead to abscess formation [24]. Oesophageal resection is performed either via thoracotomy or transperitoneally. Transperitoneal access is reserved for strictures located below the tracheal bifurcation [23, 25]. In bypass surgery, 
neck anastomosis is typically performed via the retrosternal route in the anterior mediastinum.

\section{Historical overview}

Successful oesophageal resections and reconstructions have been reported since the end of the $19^{\text {th }}$ century. In 1900, Jan Mikulicz-Radecki performed the world's first transperitoneal oesophageal resection in a clinic in Wroclaw. He was also a pioneer of plastic surgery, treating stenosis of the cervical portion of the oesophagus using skin flaps, performing the first such procedure in 1886 [26]. In 1907, Roux described successful oesophageal reconstruction following partial excision using a loop of the small intestine. This method was limited by the inability to create an intestinal segment greater than $30 \mathrm{~cm}$ in length, with longer segments resulting in conduit necrosis in about $20 \%$. The mortality rate in the 1930 s was as high as $46 \%$. In 1946, Longmire improved the Roux technique by adding microvascular anastomoses of the mesenteric intestinal vessels with the internal thoracic vessels. The development of microsurgery techniques in the second half of the $20^{\text {th }}$ century also contributed to the development of methods using pediculed or free small intestine flaps for oesophageal reconstruction, even in the cervical segment [27]. In 1911, Vuillet and Kelling independently presented the anatomical basis for using the large intestine for the oesophageal reconstruction procedure. In 1914, Von Hacker described the first successful oesophageal reconstructive surgery using the large intestine. In 1951, Orsoni performed the first simultaneous oesophageal resection and reconstruction using the large intestine. In 1965, Belsey published a case series of 104 patients treated with an isoperistaltic loop of the left colon where the overall mortality rate was $4.8 \%$, following which this technique became widely used $[28,29]$. The advantage of this particular technique was the ability to perform high anastomoses, including colopharyngeal anastomoses. However, it was not until 1978 that Akiyama demonstrated that the stomach can also be successfully used for anastomoses with the cervical section of the oesophagus and pharynx [28, 30]. Nowadays, it is the stomach which is the organ most frequently used in oesophageal reconstruction operations, including oncological cases [28, 29]. The work of Jezioro and his students from the Department of Gastrointestinal Surgery in Wrocław, which began in the 1960s, has significantly contributed to the development of oesophageal surgery in Poland. In this centre, both the small and large intestine have been used to replace the oesophagus [31, 32]. Long-term follow-up in replacement oesophagoplasties using the small intestine showed no negative consequences of reflux. Therefore, oesophagoplasty techniques using the jejunum and ileum have been developed and preferred over techniques combining the use of the small intestine and the large intestine together or the exclusive use of the large intestine [31, 32]. The Wroctaw Centre reports that the best replacement organ for the oesophagus is the jejunum, followed by the ileum. However, using the jejunum for reconstruction of the entire oesophagus is only possible in $30-40 \%$ of patients due to the arrangement of mesenteric vascular arcades [32]. Bernat described a two-stage reconstructive technique with conduit conditioning of the jejunum [31]. In the first stage, the jejunum, pedunculated to the $4^{\text {th }}$ mesenteric artery, is placed in a pre-sternal subcutaneous tunnel [31]. In the second stage, 4-5 weeks later, the intestine is mobilised from the subcutaneous bed. During the conditioning period, adaptive dilatation of the artery in the critical middle section of the arcade should allow for safe lengthening of the conduit of approximately $6-8 \mathrm{~cm}$. The intestine can then be moved retrosternally and anastomosed with the oesophagus at the neck [31]. Jezioro's original method involved creating a replacement oesophagus from the ileum with the caecum based on the vascularisation from the ileocecal artery. This was a difficult method due to the mesenteric vessel system and the presence of numerous lymph nodes in this area [32]. The development of microsurgical techniques has made it possible to safely replace the entire oesophagus with a long pedunculated segment of jejunum with microvascular anastomosis of the upper pedicle. Short stenosis of the cervical segment of the oesophagus, on the other hand, can be replaced with a free intestinal graft $[27,33]$.

\section{Surgical techniques}

A review of the literature does not provide a clear answer to the question of which organ constitutes the optimal replacement oesophagus [1, 2, 19, 24, 25, 29, 30, 33]. A selective approach to oesophageal resection is suggested, taking into account the age of the patient and the location of the stricture. Oesophagectomy is the preferred surgical procedure, although, in some patients, the location of the obstruction may justify a bypass procedure [23, 24]. In general, the aim is to remove the damaged oesophagus, and the location of the stricture will determine the type of resection and reconstruction.

\section{Oesophagogastroplasty}

Many authors believe that the stomach is the preferred organ for performing oesophageal replacement [30]. This view is supported by:

- consistent, good and predictable vascularisation,

- leaving a reservoir for food in case of whole stomach displacement,

- single anastomosis,

- relative ease of the procedure, with shorter operation time compared to other methods.

The reported mortality of oesophageal reconstruction using the stomach ranges from 0 to $10 \%$ [25, 34]. In Orringer's series, anastomotic leakage was observed in $9 \%$ of patients [34]. Stenosis at the oesophagogastric anastomosis is a frequent complication, occurring in $8-46 \%$ of cases $[25,34]$. Postoperative complaints, such as vomiting, regurgitation, and a feeling of fullness after meals, tend to resolve after a follow-up period of approximately nine months $[25,34]$. 


\section{Oesophagocoloplasty}

The large intestine has traditionally been considered the optimal organ for oesophageal replacement [2, 19, 24, $28,29]$. However, surgical techniques can be more complex and time-consuming, and the risk of early complications such as graft ischaemia and necrosis, anastomotic leakage, early-onset anastomotic stenosis, gastrointestinal obstruction, respiratory failure, and surgical site infection ranges from $35 \%$ to $56 \%[19,24,25,35]$. When planning surgery in patients over 35 years of age, primary bowel diseases (e.g. polyps, bowel cancer) should be excluded by performing a colonoscopy. The most dangerous complication of oesophagocoloplasty is graft necrosis; therefore, careful assessment and selection of the arterial supply of the intestinal graft, and atraumatic surgical technique to prevent pressure on the vascular pedicle, are key considerations. Wain et al. advocate routine mesenteric arteriography, which may show deviations from typical vascular anatomy in 38\% of patients [36]. Popovici also performed arteriography in all operated patients [29]. Other authors prefer transillumination of the mesentery $[24,28,35]$. The intestinal graft can be placed retrosternally, or in the posterior mediastinum. However, when choosing the retrosternal route, care should be taken to make the opening wide enough to pass the graft through the diaphragm. Some authors routinely excise the manubrium and a portion of the left clavicle and, if necessary, resect the lateral segment of the liver to eliminate any sites of potential compression which may lead to ischaemia of the bowel $[35,36]$. The choice between the right and left half of the colon, aside from the characteristics of the bowel itself, should be based mainly on which has the most favourable vasculature. The left colon is characterised by a more constant course of the marginal artery of Drummond, which is absent in no more than $5 \%$ of patients [28]. Popovici's approach to the selection of bowel segment uses the distal segment of the ileum as well as long segments of the colon up to and including the rectum [29] (Table V).

The final decision on which bowel segment to choose for oesophageal reconstruction is made intraoperatively, after trial vessel closure, and before their planned ligation. According to the literature, resection of the oesophagus and its replacement with the large intestine is characterised by a high (35-56\%) rate of early complications [19, 24, 25, 28, 35]. Thomas et al. divided significant early complications into groups of general and surgical complications [28].

General complications:

- pneumonia,

- acute respiratory distress syndrome (ARDS),

- septic shock,

- multi-organ failure,

- venous thromboembolism [24, 28, 35]:

Surgical complications:

- graft necrosis,

- proximal anastomotic leaks, distal anastomosis leaks,

intestinal-intestinal anastomosis leaks,

- gastrointestinal obstruction,

- acute pancreatitis,
- lymphorrhoea or lymphorrhagia,

- gastrointestinal bleeding,

- haemothorax, pneumothorax,

- surgical site infection [24, 28, 35].

Late complications of oesophagocoloplasty:

- stricture of oesophagocolonic anastomosis, diffuse graft

stenosis,

- reflux or heartburn, regurgitation, aspiration pneumonia,

- ulceration of the graft,

- chronic diarrhoea,

- hernia of the graft to the pleura,

- redundancy (too long, folded bowel),

- paralysis of the recurrent laryngeal nerve,

- gastrointestinal obstruction,

- scar hernia,

- early postprandial fullness [19, 24, 28].

The few studies on the long-term outcomes of reconstruction using the colon focus on outcomes of surgery for other indications such as oesophageal cancer and achalasia [28, 36]. A report by Chirica et al. [19] presented a large homogeneous group of patients in which long-term followup revealed the diagnosis of late intestinal conduit dysfunction in more than half of the operated patients, most of whom required surgical intervention. Usually surgical outcomes are characterised by an acceptable perioperative mortality rate. In this case, however, a high rate of early complications, including anastomotic leaks and postoperative strictures (Table VI), has also been observed.

\section{Reconstruction of the oesophagus using the small intestine}

The small intestine seems an ideal substitute for the oesophagus due to its matched diameter, lively peristalsis and resistance to reflux. However, its use is often not feasible. The Roux technique makes it possible to mobilise a segment of jejunum approximately $30 \mathrm{~cm}$ long, which can replace the distal part of the oesophagus. The Wrocław centre suggests that the best substitute for the oesophagus is the jejunum, followed by the ileum or the final $20 \mathrm{~cm}$ segment of the ileum together with the ascending colon [32]. Using the jejunum for the reconstruction of the entire oesophagus is only possible in $30-40 \%$ of patients due to the course of the mesenteric vascular arcades [32]. Bernat described the aforementioned technique of a two-stage reconstructive procedure with conditioning of the jejunum conduit, enabling lengthening of up to $8 \mathrm{~cm}$ [31]. The development of microsurgical techniques has made it possible to safely replace the entire oesophagus with a pediculed,

Table V. Properties of intestinal segments

\begin{tabular}{lcccc} 
Segment & $\begin{array}{c}\text { Adequate } \\
\text { diameter }\end{array}$ & Peristalsis & $\begin{array}{c}\text { Consistency } \\
\text { of vascularisation }\end{array}$ & $\begin{array}{c}\text { Anti-reflux } \\
\text { mechanism }\end{array}$ \\
Right colon & $+/-$ & $+/-$ & - & - \\
\hline Left colon & + & + & + & - \\
\hline $\begin{array}{l}\text { Ileocaecal } \\
\text { segment }\end{array}$ & ++ & ++ & $+/-$ & + \\
\hline
\end{tabular}


Table VI. Outcomes of reconstruction of the oesophagus using the colon

\begin{tabular}{lccccccccc} 
Author & $\begin{array}{c}\text { Number } \\
\text { of operated } \\
\text { patients }\end{array}$ & $\begin{array}{c}\text { Mortality } \\
(\%)\end{array}$ & $\begin{array}{c}\text { Early } \\
\text { complications } \\
(\%)\end{array}$ & $\begin{array}{c}\text { Anastomotic } \\
\text { leakage } \\
(\%)\end{array}$ & $\begin{array}{c}\text { Late } \\
\text { complications } \\
(\%)\end{array}$ & $\begin{array}{c}\text { Anastomotic Reflux Redundancy } \\
\text { stenosis } \\
(\%)\end{array}$ & $\begin{array}{c}\text { Good/ } \\
(\%)\end{array}$ & $\begin{array}{c}\text { (\%) } \\
\text { satisfactory } \\
\text { outcome }(\%)\end{array}$ \\
\hline Chirica et al. [19] & 223 & - & 56 & 15 & 55 & 29 & 11 & 5 & 77 \\
\hline Popovici [29] & 347 & 4.6 & - & 6.9 & - & 6.3 & - & 0.3 & 93 \\
\hline Wain et al. [36] & 20 & - & - & - & - & 48 & 8 & 4 & 80 \\
\hline Boukerrouche [35] & 60 & 3.3 & 45 & 16.6 & - & 8.3 & 3.3 & 3.3 & 100 \\
\hline Gerzic et al. [24] & 176 & 5.68 & 34.09 & 11.36 & 18.18 & 7.38 & - & 2.84 & 98 \\
\hline Zhou et al. [25] & 71 & 7 & 35 & 23 & - & 8.5 & - & - & - \\
\hline Włodarczyk et al. [37] & 23 & 0 & 34.7 & 17.4 & 4.3 & 4.3 & - & - & 85.7 \\
\hline
\end{tabular}

long segment of jejunum with microvascular anastomosis of the upper pedicle. Short strictures of the cervical segment of the oesophagus can be replaced with a free intestinal graft [33]. The primary limitation of small bowel oesophageal reconstruction is the requirement for specific microsurgical operative techniques.

\section{Summary}

Chemical burn of the upper gastrointestinal tract is a difficult clinical problem both in the early and late stages. Reconstructive surgery of the oesophagus is characterised by a high rate of complications, and therefore patients require close postoperative surveillance. All patients with oesophageal burns, including those undergoing surgery or endoscopic treatment, require long-term follow-up due to the increased risk of cancer development in the burn scar and anastomotic area.

\section{Disclosure}

The authors report no conflict of interest.

\section{References}

1. Contini S, Scarpignato C. Caustic injury of the upper gastrointestinal tract: a comprehensive review. World J Gastroenterol 2013; 19: 3918-3930.

2. Bonavina L, Chirica M, Skrobic O, Kluger Y, Andreollo NA, Contini S, Simic A, Ansaloni L, Catena F, Fraga GP, Locatelli C, Chiara O, Kashuk J, Coccolini F, Macchitella Y, Mutignani M, Cutrone C, Poli MD, Valetti T, Asti E, Kelly M, Pesko P. Foregut caustic injuries: results of the world society of emergency surgery consensus conference. World J Emerg Surg 2015; 10: 44.

3. Kardon EM. Caustic Ingestions. Available at: https://emedicine.medscape. com/article/813772-overview (8.11.2020).

4. Rollin M, Jaulim A, Vaz F, Sandhu G, Wood S, Birchall M, Dawas K. Caustic ingestion injury of the upper aerodigestive tract in adults. Ann R Coll Surg Engl 2015; 97: 304-307.

5. Chirica M, Resche-Rigon M, Bongrand NM, Zohar S, Halimi B, Gornet JM, Sarfati E, Cattan P. Surgery for caustic injuries of the upper gastrointestinal tract. Ann Surg 2012; 256: 994-1001.

6. Andreoni B, Farina ML, Biffi R, Crosta C. Oesophageal perforation and caustic injury: emergency management of caustic ingestion. Dis Esophagus 1997; 10: $95-100$.

7. Cheng HT, Cheng CL, Lin CH, Tang JH, Chu YY, Liu NJ, Chen PC. Caustic ingestion in adults: the role of endoscopic classification in predicting outcome. BMC Gastroenterol 2008; 8: 31.

8. Kochhar R, Poornachandra KS. Intralesional steroid injection therapy in the management of resistant gastrointestinal strictures. World J Gastrointest Endosc 2010; 2: 61-68.

9. Mowry JB, Spyker DA, Brooks DE, Zimmerman A, Schauben JL. 2015 Annual Report of the American Association of Poison Control Centers' National Poison Data System (NPDS): 33rd Annual Report. Clin Toxicol 2016; 54: 924-1109.
10. Lupa M, Magne J, Guarisco JL, Amedee R. Update on the diagnosis and treatment of caustic ingestion. Ochsner J 2009; 9: 54-59.

11. Cheng HT, Cheng CL, Lin CH, Tang JH, Chu YY, Liu NJ, Chen PC. Caustic ingestion in adults: the role of endoscopic classification in predicting outcome. BMC Gastroenterol 2008; 8: 31.

12. Zargar SA, Kochhar R, Nagi B, Mehta S, Mehta SK. Ingestion of corrosive acids. Spectrum of injury to upper gastrointestinal tract and natural history. Gastroenterology 1989; 97: 702-707.

13. Rigo GP, Camellini L, Azzolini F, Guazzetti S, Bedogni G, Merighi A, Bellis L, Scarcelli A, Manenti F. What is the utility of selected clinical and endoscopic parameters in predicting the risk of death after caustic ingestion? Endoscopy 2002; 34: 304-310.

14. Ryu HH, Jeung KW, Lee BK, Uhm JH, Park YH, Shin MH, Kim HL, Heo T, Min YI. Caustic injury: can CT grading system enable prediction of oesophageal stricture? Clin Toxicol 2010; 48: 137-142.

15. Bruzzi M, Chirica M, Resche-Rigon M, Corte H, Voron T, Sarfati E, Zagdanski AM, Cattan P. Emergency computed tomography predicts caustic oesophageal stricture formation. Ann Surg 2019; 270: 109-114.

16. Betalli P, Falchetti D, Giuliani S, Pane A, Dall'Oglio L, de Angelis GL, Caldore M, Romano C, Gamba P, Baldo V; Caustic Ingestion Italian Study Group. Caustic ingestion in children: is endoscopy always indicated? The results of an Italian multicenter observational study. Gastrointest Endosc 2008; 68: 434-439.

17. Zargar SA, Kochhar R, Mehta S, Mehta SK. The role of fiberoptic endoscopy in the management of corrosive ingestion and modified endoscopic classification of burns. Gastrointest Endosc 1991; 37: 165-169.

18. De Lusong MAA, Timbol ABG, Tuazon DJS. Management of oesophageal caustic injury. World J Gastrointest Pharmacol Ther 2017; 8: 90-98.

19. Chirica M, Veyrie N, Munoz-Bongrand N, Zohar S, Halimi B, Celerier M, Cat$\tan$ P, Sarfati E. Late morbidity after colon interposition for corrosive oesophageal injury: risk factors, management, and outcome. A 20-years experience. Ann Surg 2010; 252: 271-280.

20. Hopkins RA, Postlethwait RW. Caustic burns and carcinoma of the esophagus. Ann Surg 1981; 194: 146-148.

21. Appelquist P, Salmo P. Lye corrosion carcinoma of the esophagus: a review of 63 cases. Cancer 1980; 45: 2655-2658.

22. Ruol A, Rampado S, Parenti A, Portale G, Giacomelli L, Battaglia G, Cagol M, Ancona E. Caustic ingestion and oesophageal cancer: intra- and peri-tumoral fibrosis is associated with a better prognosis. Eur J Cardiothorac Surg 2010; 38: 659-664.

23. Wu MH, Lai WW. Oesophageal reconstruction for oesophageal strictures or resection after corrosive injury. Ann Thorac Surg 1992; 53: 798-802.

24. Gerzic ZB, Knezevic JB, Milicevic MN, Jovanovic BK. Esophagocoloplasty in the management of postcorrosive strictures of the esophagus. Ann Surg 1990; 211: 329-336.

25. Zhou JH, Jiang YG, Wang RW, Lin YD, Gong TQ, Zhao YP, Ma Z, Tan QY. Management of corrosive oesophageal burns in 149 cases. J Thoracic Cardiovasc Surg 2005; 130: 449-55.

26. Kielan W, Lazarkiewicz B, Grzebieniak Z, Skalski A, Zukrowski P. Jan MikuliczRadecki: one of the creators of world surgery. Keio J Med 2005; 54: 1-7.

27. Yasuda T, Shiozaki H. Oesophageal reconstruction using a pedicled jejunum with microvascular augmentation. Ann Thorac Cardiovasc Surg 2011; 17: 103-109.

28. Thomas P, Fuentes P, Giudicelli R, Reboud E. Colon interposition for oesophageal replacement: current indications and long-term function. Ann Thorac Surg 1997; 64: 757-764. 
29. Popovici Z. A new philosophy in oesophageal reconstruction with colon. Thirty-years experience. Dis Esophagus 2003; 16: 323-327.

30. Akiyama H, Miyazono H, Tsurumaru M, Hashimoto C, Kawamura T. Use of the stomach as an oesophageal substitute. Ann Surg 1978; 188: 606-610.

31. Bernat M, Bader O, Zimmer Z, Blaszczuk J, Kosz J. Jejunum für die retrosternale Rekonstruktion des Osophagus [The jejunum for the retrosternal reconstruction of the esophagus]. Zentralbl Chir 1984; 109: 1076-1080.

32. Bernat M, Bader O, Milnerowicz S, Grabowski K, Rosinka T, Blaszczuk J. Kolon oder lleum für die Rekonstruktion des gesamten Osophagus je nach dem Gefässverlauf [Colon or ileum for reconstruction of the total esophagus with reference to vascularization]. Zentralbl Chir 1985; 110: 1297-1303.

33. Ascioti AJ, Hofstetter WL, Miller MJ, Rice DC, Swisher SG, Vaporciyan AA, Roth JA, Putnam JB, Smythe WR, Feig BW, Mansfield PF, Pisters PW, Torres
MT, Walsh GL. Long-segment, supercharged, pedicled jejunal flap for tota oesophageal reconstruction. J Thorac Cardiovasc Surg 2005; 130: 1391-1398.

34. Orringer MB, Marshall B, Stirling MC. Transhiatal esophagectomy for benign and malignant disease. J Thorac Cardiovasc Surg 1993; 105: 265-276.

35. Boukerrouche A. Left colonic graft in oesophageal reconstruction for caustic stricture: mortality and morbidity. Dis Esophagus 2013; 26: 788-93.

36. Wain JC, Wright CD, Kuo EY, Moncure AC, Wilkins EW Jr, Grillo HC, Mathisen DJ. Long-segment colon interposition for acquired oesophageal disease. Ann Thorac Surg 1999; 67: 313-317.

37. Włodarczyk J, Smęder T, Kużdżał J. Surgical treatment results of burn-related oesophageal strictures. World J Surg 2017; 41: 790-795. 